\title{
Euthyroid Condition
}

National Cancer Institute

\section{Source}

National Cancer Institute. Euthyroid Condition. NCI Thesaurus. Code C132054.

Derangement of the thyroid gland or thyroid hormone metabolism that is unaccompanied by signs or symptoms of hypothyroidism or hyperthyroidism. 